\title{
MODE OF SPREAD IN THE EARLY PHASE OF LYMPHATIC METASTASIS IN NON-SMALL-CELL LUNG CANCER: SIGNIFICANCE OF NODAL MICROMETASTASIS
}

Jakob R. Izbicki, MD ${ }^{\mathrm{a}, \mathrm{c}, \mathrm{d}}$

B. Passlick, MD ${ }^{\text {a,c }}$

S. B. Hosch, MD

B. Kubuschock, $\mathrm{MD}^{\mathrm{a}, \mathrm{c}}$

C. Schneider, $\mathrm{MD}^{\mathrm{d}}$

C. Busch, MD

W. T. Knoefel, MD

O. Thetter, MD $\mathrm{M}^{\mathrm{a}, \mathrm{c}}$

K. Pantel, MD
The impact of lymphatic micrometastases on prognosis of non-small-cell lung cancer has not been clearly established. We therefore prospectively assessed the frequency, mode of mediastinal spread, and prognostic significance of lymphatic micrometastases in lymph nodes of 93 patients with completely resected nonsmall-cell lung cancer staged as pT1 to pT4 pN0 and pN1 by conventional histopathologic techniques. Frozen tissue sections from 471 lymph nodes that were staged as free of metastases by routine histopathologic examination were screened for micrometastases by the alkaline phosphatase-antialkaline phosphatase immunostaining technique with the monoclonal antibody Ber-Ep-4. Twenty of 73 patients $(27.4 \%)$ with disease staged as pN0 and nine of 20 patients $(45.0 \%)$ with disease staged as pN1 had nodal micrometastases. Eight of 17 patients with upper lobe primary tumors and five of 12 patients with lower lobe primary tumors exhibited skip micrometastases. Mean relapse-free survival was significantly increased in patients with pN0 disease without micrometastases (41.1 vs 29 months, $p=0.0081$ ). In patients with $\mathrm{pN} 1$ disease, mean relapse-free and cancer-related survivals were also significantly increased if no micrometastases were found (34.8 and 38.2 months vs 18 and 23.5 months, $p=0.0157$ and $p=$ 0.0094). Patients with disease staged as pNo and pN1 with micrometastases revealed no difference in cancer-related survival compared with a control population of patients with disease staged as $\mathrm{pN} 2$. The mode of spread was erratic. The prognosis of patients after upstaging of $\mathrm{pNO}$ and pN1 disease according to results of immunohistochemical staining correlated strongly with the prognosis of patients whose disease was staged at the higher stages by conventional histopathologic examination. These findings could represent a new indication for adjuvant therapy, supporting extensive lymph node sampling for staging purposes. (J Thorac Cardiovasc Surg 1996;112:623-30)
$\mathrm{M}$ ediastinal lymph node involvement in nonsmall-cell lung cancer is a crucial factor in prognosis. Even patients with negative lymph nodes

From the Department of Surgery, ${ }^{\mathrm{a}}$ and Institute for Immunology, University of Munich, Munich, Division of Thoracic Surgery, Zentralkrankenhaus Gauting, ${ }^{c}$ and Department of Surgery, ${ }^{\mathbf{d}}$ University of Hamburg, Hamburg, Germany.

Supported by grants of the MMW Herausgeberstiftung, Munich, Germany, the Dr. Mildred Scheel Stiftung/Deutsche Krebshilfe, Bonn, Germany, the Wilhelm-Sander-Stiftung, Neuburg/Donau, Germany, the Friedrich-Baur-Stiftung, Munich, Germany, and the K. L. Weigand Stiftung, Munich, Germany.

Received for publication April 24, 1995; revisions requested Sept. 13, 1995; revisions received Jan. 17, 1996; accepted for publication Jan. 25, 1996.

Address for reprints: Jakob R. Izbicki, MD, Department of Surgery, University of Hamburg, Martinistrasse 52, 20246 Hamburg-Germany.

Copyright (C) 1996 by Mosby-Year Book, Inc.

$0022-5223 / 96 \$ 5.00+0 \quad \mathbf{1 2 / 1 / 7 2 3 2 5}$ and pT1 or pT2 lesions, however, have a $40 \%$ chance of recurrent disease within the first 2 years after an intended curative operation. ${ }^{1,2}$ Early micrometastatic tumor spread not detectable by current preoperative staging procedures and histopathologic examination must therefore be assumed.

Recently, the specific detection of individual epithelial tumor cells in bone marrow and lymph nodes by immunocytochemical and histochemical assay employing monoclonal antibodies became possible. ${ }^{3-6}$ The evaluation of bone marrow provides information about systemic tumor cell dissemination. Regional tumor cell dissemination is immunohistochemically assessed by screening for micrometastases in lymph nodes that are missed by routine histopathologic examination. ${ }^{7}$ The conjunction of radical systematic lymphadenectomy with this immunohistochemical staining method should lead to an accurate description of mediastinal spread and to 
evaluation of the early stage of lymphogenic metastasis in bronchogenic carcinoma. We therefore performed a prospective study to assess frequency, mode of mediastinal spread, and prognostic significance of lymphatic micrometastases in lymph nodes of patients with completely resected non-small-cell lung cancer and no conventional histologic evidence of mediastinal nodal disease.

\section{Patients and methods}

This study was approved by the ethics committee of the University of Munich.

Patients. Lymph nodes and tumor samples were collected from 129 patients with operable non-small-cell lung cancer treated by lobectomy or pneumonectomy in combination with mediastinal lymphadenectomy, as described elsewhere, ${ }^{8}$ between October 1989 and December 1991. Informed consent was obtained from all patients before their inclusion in the study. Ninety-three patients with disease staged by postoperative histopathologic and clinical examination as without evident metastasis to the $\mathrm{N} 2$ region ( $\mathrm{pT} 1$ to $\mathrm{pT} 4, \mathrm{pN} 0$ and $\mathrm{pN} 1, \mathrm{pM} 0, \mathrm{R} 0$ ) were identified and represent the population for this study. The remaining 36 patients with lymph node involvement of mediastinal nodes ( $\mathrm{pN} 2$ disease) were used as control group. Tumor stage and grading were classified according to the 4th edition of the TNM classification of the International Union Against Cancer. ${ }^{9}$ Patients were excluded if they had evidence of intrapulmonary metastases or if the resected specimen exhibited residual tumor at the resection margin. Patients whose tumors were subsequently classified as small-cell lung cancer were also excluded.

After primary operation, patients were reexamined every 3 months for 2 years and thereafter at 6 -month intervals. The evaluation included physical examination, plain chest radiography, bronchoscopy, computed tomography of the chest, abdominal ultrasonography, and bone scan.

Histopathologic analysis and tissue preparation. At primary operation, lymph nodes of the ipsilateral thoracic cavity were removed by mediastinal lymphadenectomy and mapped by the surgeon according to the mapping scheme of the American Thoracic Society. ${ }^{10}$

All resected lymph nodes were divided into two parts. One part was embedded in paraffin for routine histopathologic staging (hematoxylin-eosin stain [HE]): the other part and a representative sample of the primary tumor were snap-frozen in liquid nitrogen within 3 hours after removal and stored at $-80^{\circ} \mathrm{C}$ until use. Lymph nodes from patients who had no evidence of nodal metastases of the $\mathrm{N} 2$ region (mediastinal lymph nodes) by routine histopathologic analysis were screened by means of immunohistochemistry. We used the antiepithelial monoclonal antibody Ber-Ep-4 (immunoglobulin $\mathrm{G}_{1}$ ), which is commercially available (Dako, Hamburg, Germany) and can be used on snap-frozen and paraffinembedded material for the detection of micrometastatic tumor cells as described elsewhere. ${ }^{7}$ Briefly, Ber-Ep-4 is directed against two glycopolypeptides of 34 and $49 \mathrm{kd}$ present on the surface and in the cytoplasm of all epithelial cells, except for the superficial layers of squamous epithelia, hepatocytes, and parietal cells. The antibody does not react with mesenchymal tissue, including lymphoid tissue, and can also be used on paraffin-fixed ${ }^{11,12}$ sections.

From each lymph node, 4 to $6 \mu \mathrm{m}$ sections were cut by cryostat from three different levels and transferred onto glass slides pretreated with 3-triethoxysilyl-propylamin (Merck, Darmstadt, Germany). One section per level was stained with the alkaline phosphatase-antialkaline phosphatase technique. Briefly, cryostat-cut sections were fixed in acetone for 10 minutes at room temperature, air-dried, rehydrated, and preincubated with antibody-serum complex (diluted 1:10 with tris-phosphatase buffered saline solution) for 20 minutes to block unspecific bindings. The primary monoclonal antibody in appropriate dilution with antibody-serum complex (diluted 1:10 with tris-phosphatase buffered saline solution) was applied for 45 minutes at room temperature. After each incubation, repeated washings in tris-phosphatase buffered saline solution (three times for 5 minutes each) were performed. Subsequently, a rabbit-antimouse immunoglobulin G (Dako) was applied for 30 minutes, followed by the alkaline phosphatase-antialkaline phosphatase complex for another 30 minutes. Antibody-bound alkaline phosphatase activity was detected with Fast Red TT (Sigma, Deisenhofen, Germany); endogenous alkaline phosphatase was quenched by addition of levamisole. After incubation for 10 to 15 minutes, cells were counterstained with Mayer's hemalum and mounted with Kaiser's glycerinated gelatin.

The specificity of this method had been previously evaluated by our group with lymph nodes from control patients with nonepithelial tumors or inflammatory diseases. ${ }^{7}$ The sensitivity of Ber-Ep-4 was determined as $99 \%$ by staining of cryostat-cut sections of primary tumor samples. ${ }^{7}$ Sections of normal colon mucosa served as positive control preparations. Isotype-matched, irrelevant murine monoclonal antibodies served as negative control preparations (MOPC 21 or immunoglobin G1; Sigma). To evaluate the effectiveness of immunostaining in comparison with HE staining, adjacent sections of Ber-Ep-4positive sections were stained with HE. Tumor cells could be detected by HE staining in none of these control sections (Fig. 1).

A nodal micrometastasis in a given lymph node found to be tumor free by routine histopathologic staining was defined as the presence of single cells with positive Ber-Ep-4 staining or a cluster of cells with positive Ber-Ep-4 staining with a size of not more than $2 \mathrm{~mm}$ within the body of the lymph node (Fig. 1). Multiple micrometastatic lymph nodes within one level were considered to represent one metastatic focus. Patients were excluded from analysis if immunohistochemical and histopathologic reexamination revealed nodal metastases larger than $2 \mathrm{~mm}$.

For analysis of the mode of micrometastatic nodal spread to the mediastinum, patients were divided into four groups according to the location of the primary tumor. One group had right upper lobe primary tumors, one group had right middle or lower lobe primary tumors, 
one group had left upper lobe primary tumors, and one group had left lower lobe primary tumors.

The mediastinal nodes were separated into two regions, the upper and lower mediastinum. The upper mediastinum contained node levels 1 through 4 on the right side and node levels 1 through 6 on the left side. The lower mediastinum contained node levels 7 through 9. Locoregional nodes comprised node levels 10 through 14 (N1 region).

If the primary lesion was located in the upper lobe, the upper mediastinum was designated as the regional mediastinum and the lower mediastinum was designated as the nonregional mediastinum. In lower-lobe lesions, the lower mediastinum was designated as the regional mediastinum and the upper mediastinum was designated as the nonregional mediastinum. ${ }^{13}$

Statistical analysis. Differences in the relative frequency of nodal micrometastases were compared by $\chi^{2}$ test with Yates's correction. Recurrence-free, distant metastasis-free interval, cancer-related survival, and relapsefree survival were calculated with the Kaplan-Meier method. Log-rank tests were used for comparison of Kaplan-Meier-curves. The Cox proportional-hazards model was applied for multivariate analysis. For this analysis, all variables were dichotomized. The level of significance was set to a $p$ value of less than 0.05 .

\section{Results}

Patient characteristics. There were 95 patients whose primary tumors were initially classified as pT1 to $\mathrm{pT} 4$ and $\mathrm{pN} 0$ to $\mathrm{pN} 1$. Two patients were excluded from analysis because histopathologic reexamination and repeated immunohistochemistry revealed gross nodal metastases larger than $2 \mathrm{~mm}$ in size in the $\mathrm{N} 2$ region. Of the eligible patient population, 84 were available for follow-up analysis.

The mean age was 60 years, with a range of 38 to 80 years. Primary tumors were located in the right upper lobe in 29 cases $(31.3 \%)$, in the left upper lobe in 29 cases $(31.3 \%)$, in the right middle or lower lobe in 19 cases $(20.4 \%)$, and in the left lower lobe in 16 cases $(17.2 \%)$. Tumors were typed and staged as depicted in Table I.

Incidence of nodal micrometastases. Application of the immunohistochemical assay to cryostat-cut sections of 471 lymph nodes from 93 patients whose disease was staged by conventional histopathologic examination as $\mathrm{pN} 0$ or $\mathrm{pN} 1$ showed single cells or cell clusters $2 \mathrm{~mm}$ size or smaller with positive Ber-Ep-4 staining in 38 nodes $(8.1 \%)$ in 29 patients (31.2\%; Fig. 1). Twenty of 73 patients $(27.4 \%)$ with disease staged as pNo had nodal micrometastases, versus nine of 20 patients $(45.0 \%)$ with stage $\mathrm{pN} 1$ disease (not significant). Only one node level was affected in 21 patients, and two node levels were affected in seven patients. One patient exhibited

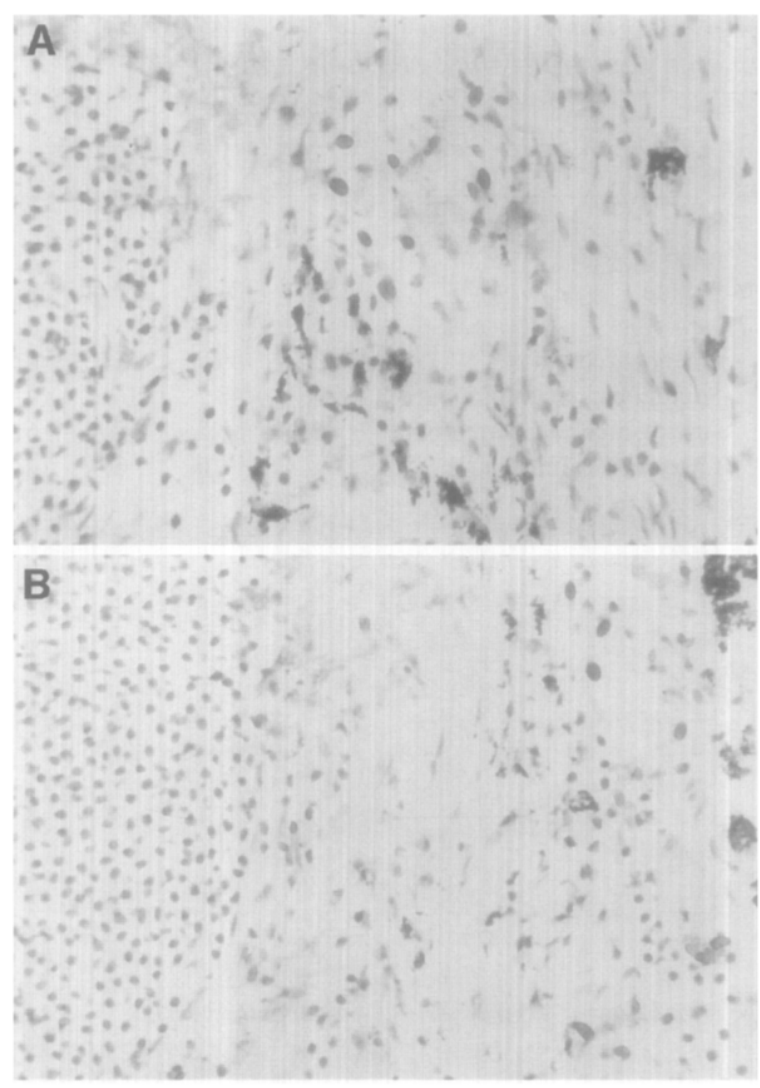

Fig. 1. A, Micrometastasis in a histopathologically negative lymph node detected with the monoclonal antibody Ber-Ep4. B, Adjacent section stained with HE does not reveal tumor cells.

micrometastatic foci at three node levels. Fifteen patients had as many as three disseminated cells in the body of the nodes, eight additional patients had cell clusters of between four and 200 cells, and one patient exhibited a micrometastatic focus $2 \mathrm{~mm}$ in size.

Effect of histologic type on extent of mediastinal nodal micrometastasis. Of 42 patients with adenocarcinoma, 13 patients had one-level metastases, one had two-level metastases, and one patient exhibited three-level metastases. Of the 40 patients with squamous cell carcinoma, seven patients had one-level metastases and five patients had two-level metastases (not significant).

Effect of primary tumor location on skip mediastinal nodal micrometastasis. Table II shows the relationship between location of the primary tumor and prevalence of skip mediastinal nodal micrometastasis. 
Table I. Patient and tumor characteristics of 129 patients with non-small-cell lung cancer

\begin{tabular}{|c|c|c|c|c|}
\hline & \multicolumn{2}{|c|}{$p N O, p N 1$} & \multicolumn{2}{|c|}{$p N 2$} \\
\hline & $n$ & $\%$ & $n$ & $\%$ \\
\hline \multicolumn{5}{|l|}{ Sex } \\
\hline male & 68 & 73 & 27 & 75 \\
\hline female & 25 & 27 & 9 & 25 \\
\hline \multicolumn{5}{|l|}{ Tumor type } \\
\hline Adenocarcinoma & 42 & 45.2 & 13 & 36 \\
\hline Squamous cell carcinoma & 40 & 43 & 16 & 44 \\
\hline Adenosquamous carcinoma & 3 & 3.2 & 2 & 6 \\
\hline Large-cell carcinoma & 8 & 8.6 & 5 & 14 \\
\hline \multicolumn{5}{|l|}{ Tumor stage } \\
\hline Stage I & 66 & 71 & 0 & 0 \\
\hline Stage II & 13 & 14 & 0 & 0 \\
\hline Stage IIIa & 12 & 12.8 & 33 & 92 \\
\hline Stage IIIb & 2 & 2.2 & 3 & 8 \\
\hline \multicolumn{5}{|l|}{$T$ stage } \\
\hline $\mathrm{T} 1$ & 21 & 22.5 & 2 & 6 \\
\hline $\mathrm{T} 2$ & 58 & 62.4 & 27 & 75 \\
\hline $\mathrm{T} 3$ & 13 & 14 & 4 & 11 \\
\hline $\mathrm{T} 4$ & 1 & 1.1 & 3 & 8 \\
\hline \multicolumn{5}{|l|}{$N$ stage } \\
\hline No & 73 & 78.5 & 0 & 0 \\
\hline N1 & 20 & 21.5 & 0 & 0 \\
\hline $\mathrm{N} 2$ & 0 & 0 & 36 & 100 \\
\hline
\end{tabular}

Age ranged from 38 to 80 years, with a mean of 60 years.

Skip micrometastases were defined as metastatic foci in the nonregional mediastinum without involvement of the regional mediastinum or metastatic foci in the regional or nonregional mediastinum without metastases in locoregional nodes. Eight of 17 patients with primary tumors of the upper lobe exhibited skip metastases, versus five of 12 patients with primary tumors of the lower lobe (not significant).

\section{Effect of micrometastases on survival}

Relapse-free and overall cancer-related survival. Among the 67 patients available for follow-up with a histopathologic nodal stage of N0, 51 patients had disease classified without nodal micrometastases by our immunohistochemical assay. Their mean relapse-free survival and cancer-related survival were 41.1 months and 44.6 months, respectively. For the 16 patients with nodal micrometastases, the mean relapse-free survival and cancer-related survival were 29.0 months and 36.5 months, respectively ( $p=0.0081, p=0.0584$; Fig. 2 ; Table III). Patients with histopathologic stage N1 disease without further nodal micrometastases ( $n=11$ ) exhibited mean relapse-free survival of 34.8 months and cancerrelated survival of 38.2 months, compared with six
Table II. Location of primary tumor and skip nodal micrometastases

\begin{tabular}{lcc}
\hline Primary tumor site & No skip metastases & Skip metastases \\
\hline N0 group & & \\
RUL $(n=6)$ & 2 & 4 \\
LUL $(n=5)$ & 4 & 1 \\
RMLL $(n=4)$ & 2 & 2 \\
LLL $(n=5)$ & 2 & 3 \\
N1 group & & \\
RUL $(n=4)$ & 2 & 3 \\
LUL $(n=2)$ & 1 & 1 \\
RMLL $(n=2)$ & 2 & 0 \\
LLL $(n=1)$ & 1 & 0 \\
\hline
\end{tabular}

Skip metastases were defined as metastatic foci in the nonregional mediastinum without metastasis to the regional mediastinum or metastatic foci in the regional or nonregional mediastinum without metastases in locoregional nodes. RUL, Right upper lobe; $L U L$, left upper lobe; $R M L L$, right middle or lower lobe; $L L L$, left lower lobe

patients with nodal micrometastases who had mean relapse-free and cancer-related survivals of 18.0 months and 23.5 months, respectively $(p=0.0157$, $p=0.0094$ ). To determine whether the immunohistochemical documented $\mathrm{N}$ stage is an independent prognostic factor for relapse-free survival, we performed a multivariate analysis with a Cox regression model. This analysis revealed the independent prognostic influence on disease-free survival of the presence of micrometastases in lymph nodes free of metastases according to histopathologic analysis ( $p=0.011$, relative risk 3.1 ; Table 4 ). Regarding cancer-related survival, multivariate analysis also demonstrated an independent prognostic influence of the presence of micrometastases $(p=0.049$, relative risk 2.9; data not shown).

Local recurrence-free and distant metastasis-free intervals. The mean local recurrence-free interval for patients with pN0 tumors without nodal micrometastases was 47.9 months; that for patients with nodal micrometastases was 31.9 months $(p=0.0001)$. In patients with $\mathrm{N} 1$ disease without nodal micrometastases, the mean local recurrence-free interval was 35.7 months; that for patients with nodal micrometastases was 27.7 months (not significant).

The mean distant metastasis-free interval for patients with N0 disease without nodal micrometastases was 45.1 months; that for patients with nodal micrometastases was 38.8 months (not significant). In patients with pathologic N1 stage disease without nodal micrometastases, the mean distant metastasis-free interval was 39.2 months; that for patients with nodal micrometastases was 20.7 months $(p=0.0038)$. 


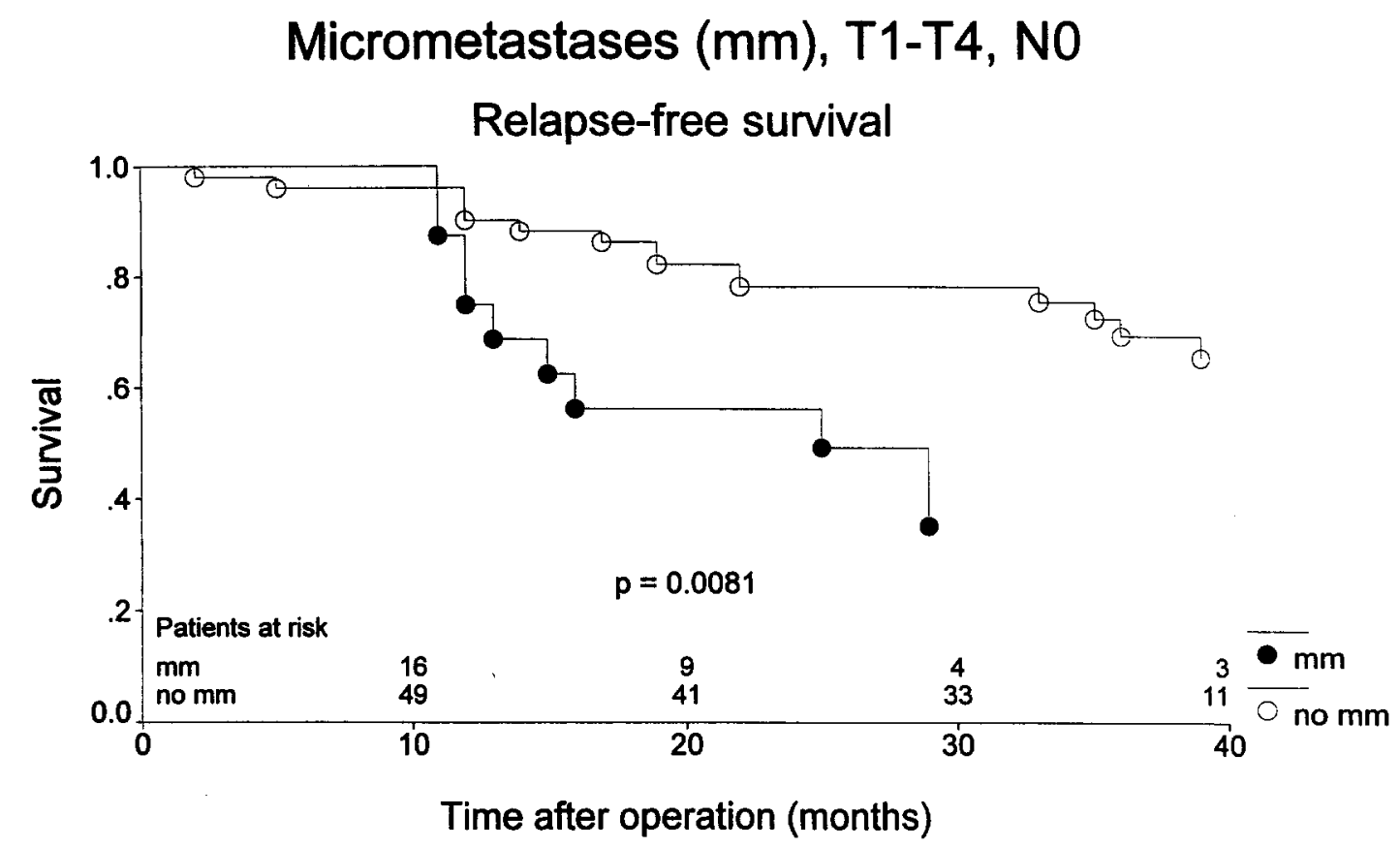

Fig. 2. Relapse-free survival curves among patients with $(n=22)$ and without $(n=62)$ micrometastases for stage $\mathrm{pT} 1$ to $\mathrm{pT} 4 \mathrm{pN} 0(p=0.0081)$.

Table III. Effects of micrometastases on survival

\begin{tabular}{lccc}
\hline & Relapse-free suvival & Cancer-related survival & Local recurrence-free interval \\
\hline $\mathrm{pN} 0(n=67)$ & & & \\
Without micrometastases $(n=51)$ & 41.1 & 44.6 & 47.9 \\
With micrometastases $(n=16)$ & 29.0 & 36.5 & 35.7 \\
$p$ & 0.0081 & 0.0584 & 0.001 \\
$\mathrm{pN} 1(n=17)$ & & & \\
Without micrometastases $(n=11)$ & 34.8 & 38.2 & 31.9 \\
With micrometastases $(n=6)$ & 18.0 & 23.5 & $\mathrm{NS}$ \\
$p$ & 0.0157 & 0.0094 & - \\
Upstaging & - & 21.8 & - \\
pN2, no micrometastases $(n=36)$ & - & 28.6 & - \\
pN0, pN1 with micrometastases $(n=22)$ & - & $\mathrm{NS}$ & - \\
$p$ & & & \\
\hline
\end{tabular}

NS, Not significant.

Extent of nodal micrometastatic involvement and prognosis. Among patients with pN0 disease, there was no significant correlation between cancer-related survival and extent of micrometastatic nodal involvement (number of micrometastatic node levels). Five of 11 patients with only one node level involved died of disease (mean survival 33.2 months) compared with two of five patients with more than one level involved who died of disease (mean survival 34.8 months, (not significant). Micrometastatic skip nodal involvement had no influence on distant metastasis-free interval, local recurrencefree interval, relapse-free survival, and overall cancerrelated survival (data not shown).

The size of nodal micrometastases (comparison between three or fewer disseminated cells and more than three cells) showed no statistically significant differences with respect to relapse-free and cancerrelated survivals and distant metastasis-free and local recurrence-free intervals. This lack of significant differences indicates that the detection of even single epithelial cells is an indicator of disseminated 


\section{Size of micrometastases, T1-T4, N0-N1}

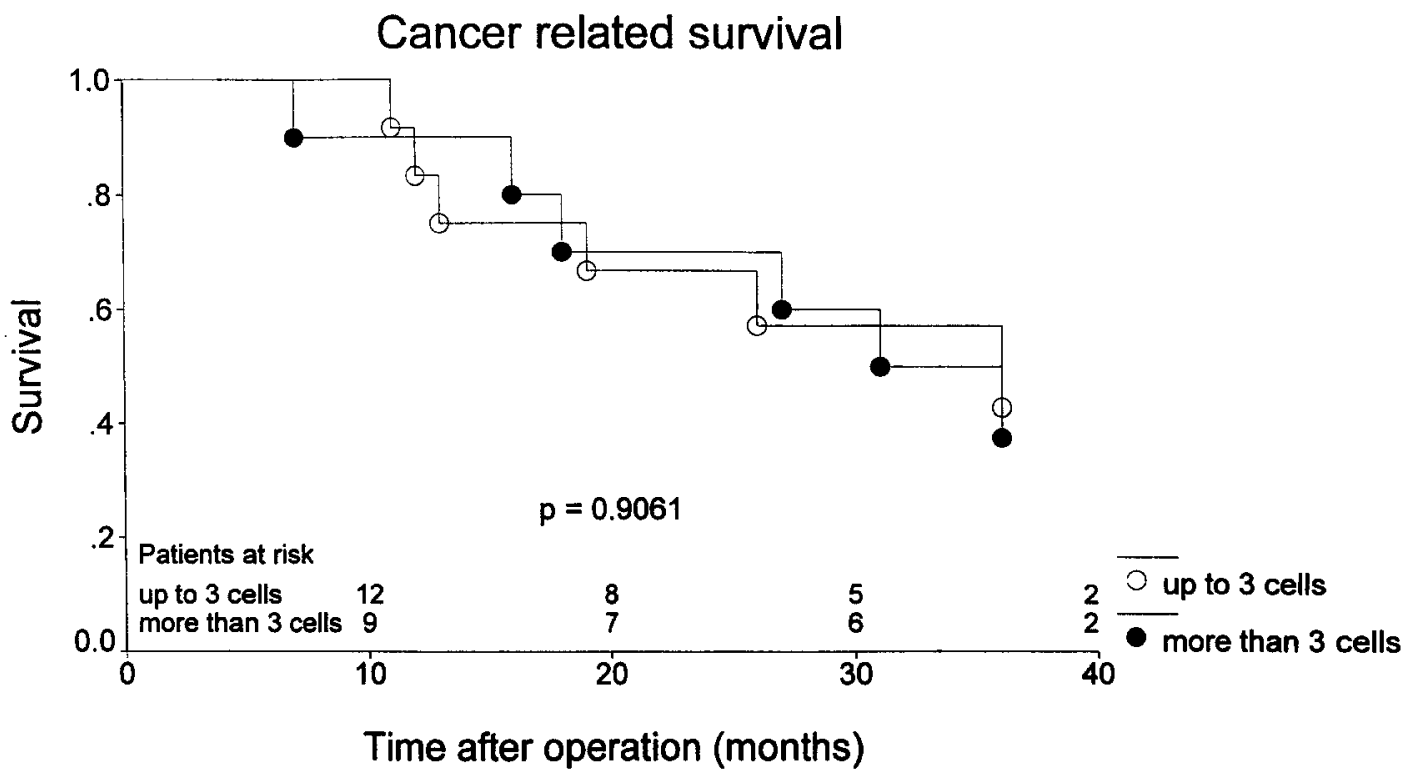

Fig. 3. Cancer-related survival curves for patients with three or fewer disseminated cells $(n=12)$ and with more than three disseminated cells $(n=10$, not significant).

Table IV. Multivariate analysis of relapse-free survival

\begin{tabular}{lcccc}
\multicolumn{1}{c}{ Risk factor } & Standard & \multicolumn{2}{c}{$\begin{array}{c}\text { Relative risk } \\
\text { (95\% confidence interval) }\end{array}$} \\
\hline pT1 and pT2 vs pT3 and pT4 & Estimated coefficient & error & $p$ & (95\% \\
Adenocarcinoma vs squamous cell carcinoma & 0.44 & 0.62 & 0.476 & $1.56(0.46-5.24)$ \\
pN0 vs pN1 & -0.16 & 0.40 & 0.695 & $0.86(0.39-1.87)$ \\
Immunohistochemical N0 vs immunohistochemical N1 and N2 & -0.50 & 0.58 & 0.383 & $0.61(0.20-1.87)$ \\
\end{tabular}

tumor disease. It must be noted, however that the numbers in this stratification are rather small (Fig. 3).

Comparison between patients with disease staged as N0 or N1 with nodal micrometastases and a control population of 36 patients with pathohistologically proved N2 stage disease revealed no statistical difference in cancer-related survival (Fig. 4). The same was true for relapse-free, local recurrence-free, and distant metastasis-free survivals.

\section{Discussion}

The addition of specific immunohistochemical assays to the evaluation of lymph nodes in resected non-small-cell lung cancer provides an effective tool to assess the mode of early mediastinal lymphatic spread. In particular, the predominant sites of nodal metastases can be identified.
A nodal micrometastasis was defined as a single disseminated cell with positive Ber-Ep4-staining within the body of the lymph nodes or clusters of such cells up to a size of $2 \mathrm{~mm}$. This classification is in accordance with the definition given by Attiyeh and associates ${ }^{14}$ and Huvos, Hutter, and Berg. ${ }^{15}$ Most of these micrometastases, however, are much smaller than the limit of $2 \mathrm{~mm}$. In our series, $52 \%$ of the micrometastases had three or fewer disseminated cells, and only one patient showed a micrometastatic lesion of $2 \mathrm{~mm}$. Because no significant difference was seen between the incidence of cells with positive Ber-Ep-4 staining in patients with disease staged as $\mathrm{pN} 0$ and those with disease staged as $\mathrm{pN} 1$, early micrometastatic disease seems to be a feature of the continuously developing tumor spread and not merely an initiating phenomenon.

Most tumors exhibited one-level metastases, re- 


\section{N0-N1 with vs. N2 without micrometastases $(\mathrm{mm})$}

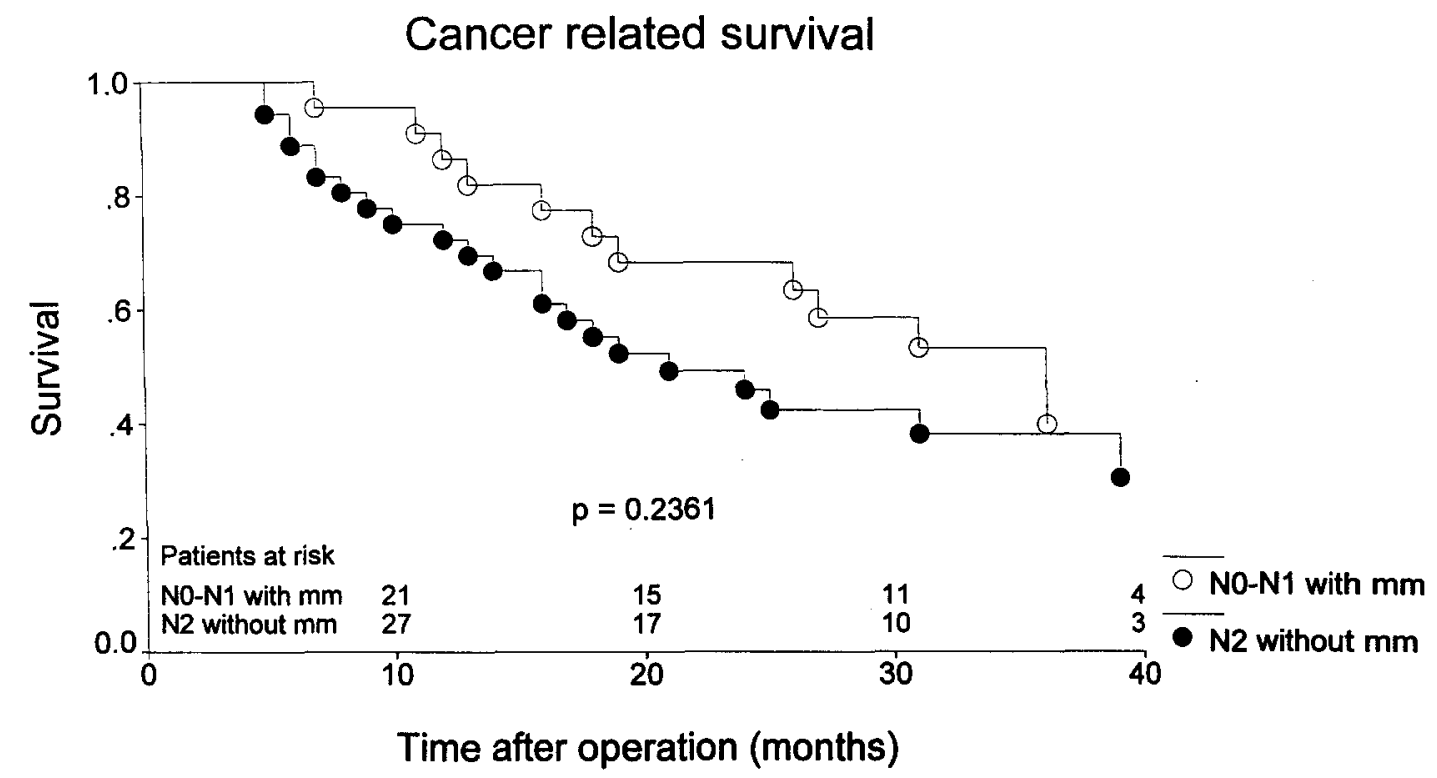

Fig. 4. Cancer-related survival curves for pT1 to pT4 pN0 to pN1 patients with micrometastases $(n=22)$ and patients with pT1 to pT4 pN2 disease $(n=36$, not significant).

gardless of tumor type. In addition, the location of the tumor had no influence on the extent of nodal spread, nor on the mode of nodal involvement. To compare the lymphatic routes with respect to site of primary tumor, we divided the mediastinum into upper and lower mediastinum to study early lymphatic tumor cell dissemination to the regional and nonregional mediastinum. Micrometastatic spread in this series also occurred beyond the regional into the nonregional mediastinum without involving lymph nodes of the regional mediastinum or locoregional nodes. Eight of 17 patients (47\%) with upperlobe lesions exhibited skip metastases to the lower mediastinum, and five of 12 patients $(42 \%)$ with lower-lobe tumors showed early nodal spread in the upper mediastinum. This result is in contrast to findings of Watanabe and coworkers ${ }^{13}$ and Hata, Troidl, and Hasegawa. ${ }^{16}$ Watanabe $^{13}$ reported a frequency of skip metastases of $22 \%$ from lowerlobe lesions to the upper mediastinum and a frequency of only $8 \%$ from upper-lobe tumors to the lower mediastinum. Hata, Troidl, and Hasegawa ${ }^{16}$ demonstrated by lymphoszintigraphy that the normal lymph drainage is through the regional mediastinum. From the lower lobe, only a small quantity of dye reached the upper mediastinal lymph nodes. Because of the rather erratic mode of early lym- phatic spread, our results support the recommendation for an extensive lymph node sampling in combination with immunohistochemical studies for better postoperative staging. ${ }^{8}$

Apart from analyzing patterns of metastatic spread, we were interested in the prognostic impact of nodal micrometastatic involvement. The presence of lymph node metastases in non-small-cell lung cancer is of utmost importance to prognosis. ${ }^{17-19} \mathrm{We}$ therefore wanted to know whether micrometastatic involvement of lymph nodes exerts influences on prognosis and recurrence rate of lung cancer patients comparable to those among patients with histopathologically positive lymph nodes. In our series, 16 of 67 patients in the pN0 group and six of 17 patients in the $\mathrm{pN} 1$ group exhibited negative lymph node staging according to conventional histopathologic examination but were positive according to our immunohistochemical assessment. In both groups, a significantly decreased recurrencefree survival was seen among patients with nodal micrometastases. Regarding local recurrence-free and distant metastasis-free survival, there was a significant advantage for patients with $\mathrm{pNO}$ disease without micrometastatic involvement. In contrast, in patients with $\mathrm{pN} 1$ disease there was a prognostic benefit only for the distant metastasis-free interval. 
Cancer-related survival was also correlated with early tumor cell dissemination in lymph nodes.

More extensive nodal involvement did not significantly decrease survival in the $\mathrm{pN} 0$ group; patients with involvement of only one level and those with involvement of more than one level showed similar survivals. The prevalence of skip lesions to mediastinal lymph nodes versus regional mediastinal or locoregional lymph node involvement was of no prognostic value. In addition, the size of the micrometastases showed no significant influence on survival or recurrence. These findings indicate that even a single micrometastatic cell is a sufficient marker for advanced tumor disease, as we have pointed out elsewhere. ${ }^{7,20}$

We conclude that the prognosis of patients after upstaging of $\mathrm{pN} 0$ and $\mathrm{pN} 1$ disease according to immunohistochemical staining results correlates strongly with the prognosis according to conventional histopathologic examination for these stages. ${ }^{17-19,21}$ Early micrometastatic spread also correlates with a high rate of recurrent disease in patients with pN0 disease. These correlations support our view that the current TNM staging system, as proposed by the International Union Against Cancer in $1987,{ }^{9}$ should be further refined. Immunohistochemical assessment of nodal micrometastasis could provide such a refinement; however, a consensus should be reached regarding the definition (size) of nodal micrometastases. 7,20

In conclusion, our results provide a rationale for extensive lymph node sampling, enabling us to identify the subpopulation of patients with "false negative" lymph nodes after standard histopathologic examination. In view of the minimal residual tumor load, adjuvant therapy might be more effective for these patients than for patients with histopathologically positive lymph nodes.

\section{REFERENCES}

1. Mountain CF. A new international staging system for lung cancer. Chest 1986;89:225S-33S.

2. Immerman SC, Vanecko RM, Fry WA, Head LR, Shields TW. Site of recurrence in patients with stages I and II carcinoma of the lung resected for cure. Ann Thorac Surg 1981;32:23-7.

3. Byrne J, Waldron R, McAvinchey D, Dervan P. The use of monoclonal antibodies for the histopathological detection of mammary axillary micrometastases. J Surg Oncol 1987;13: 409-11.

4. Raymond WA, Leong AS. Immunoperoxidase staining in the detection of lymph node metastases in stage I breast cancer. Pathology 1989;21:11-5.

5. Pantel K, Izbicki JR, Angstwurm M, Braun S, Passlick B,
Karg O, et al. Immunocytological detection of bone marrow micrometastasis in operable non-small cell lung cancer. Cancer Res 1993;53:1027-1031.

6. Schlimok G, Funke I, Bock B, Schweiberer B, Witte J, Riethmueller G. Epithelial tumor cells in bone marrow of patients with colorectal cancer: immunocytochemical detection, phenotypic characterization, and prognostic significance. J Clin Oncol 1990;8:831-7.

7. Passlick B, Izbicki JR, Kubuschok B, Nakrath W, Thetter O, Pichlmeier $U$, et al. Immunohistochemical assessment of individual tumor cells in lymph nodes of patients with non-small-cell lung cancer. J Clin Oncol 1994;12:1827-32.

8. Izbicki JR, Passlick B, Karg O, Bloechle C, Pantel K, Knoefel WT, et al. Impact of radical systematic mediastinal lymphadenectomy on tumor staging in lung cancer. Ann Thorac Surg 1995:59:209-14.

9. Hermanek P, Sobin LH. TNM classification of malignant tumours. 4th ed. New York: Springer, 1987.

10. Martini N, Flehinger BJ, Zaman MB, Beattie EJ Jr. Results of resection in non-oat cell carcinoma of the lung with mediastinal lymph node metastases. Ann Surg 1983;198:386-97.

11. Momburg F, Moldenhauer G, Hammerling GJ, Moller P. Immunohistochemical study of the expression of a Mr 34,000 human epithelium-specific surface glycoprotein in normal and malignant tissues. Cancer Res 1987;47:2883-91.

12. Latza U, Niedobitek G, Schwarting R, Nekarda N, Stein H. Ber-EP4: new monoclonal antibody which distinguishes epithelia from mesothelia. J Clin Pathol 1990;43:213-9.

13. Watanabe Y, Shimizu J, Tsubota M, Iwa T. Mediastinal spread of metastatic lymph nodes in bronchogenic carcinoma: mediastinal nodal metastases in lung cancer. Chest 1990;97:1059-65.

14. Attiyeh FF, Jensen M, Huvos AG, Fracehia A. Axillary micrometastasis and macrometastasis in carcinoma of the breast. Surg Gynecol Obstet 1977;144:839-42.

15. Huvos AG, Hutter RV, Berg JW. Significance of axillary macrometastases and micrometastases in mammary cancer. Ann Surg 1971;173:44-6.

16. Hata $E$, Troidl H, Hasegawa $T$. In-vivo-Untersuchungen der Lymphdrainage des Bronchialsystems beim Menschen mit der Lympho-Szintigraphic-eine neue diagnostische Technik. In: Hamelmann $\mathrm{H}$, Troidl $\mathbf{H}$, editors. Behandlung des Bronchialkarzinoms. 1st ed. Stuttgart: Georg Thieme Verlag, 1981:27-34

17. Naruke T, Suemasu K, Ishikawa S. Lymph node mapping and curability at various levels of metastasis in resected lung cancer. J Thorac Cardiovasc Surg 1978;76:832-9.

18. Shields TW. The significance of ipsilateral mediastinal lymph node metastasis (N2 disease) in non-small cell carcinoma of the lung: a commentary. J Thorac Cardiovasc Surg 1990;99:48-53.

19. Pearson FG, DeLarue NC, Ilves R, Todd TR, Cooper JD. Significance of positive superior mediastinal nodes identified at mediastinoscopy in patients with resectable cancer of the lung. J Thorac Cardiovasc Surg 1982;83:1-11.

20. Passlick B, Izbicki JR, Kubuschok B, Thetter O, Pantel K. Lymphatic tumor cell dissemination in patients with resectable non-small cell lung cancer: impact on staging and prognosis. Ann Thorac Surg 1996;61:177-83

21. Naruke T, Goya T, Tsuchiya R, Suemasu $K$. The importance of surgery to non-small cell carcinoma of lung with mediastinal lymph node metastasis. Ann Thorac Surg 1988;46:60310. 